\title{
Relationship between Associated Persons and Subjects Domain
}

National Cancer Institute

\section{Source}

National Cancer Institute. Relationship between Associated Persons and Subjects

Domain. NCl Thesaurus. Code C147175.

A domain utilized for the submission of relationship to subject records related to persons associated with the study subject. 